\title{
Aplicação da teoria dos jogos na análise de alianças estratégicas
}

\section{The application of game theory in the analysis of strategic alliances}

\author{
Eduardo Botti Abbade ${ }^{1}$
}

\section{RESUMO}

Este estudo tem o objetivo central de discutir e compreender a aplicação da Teoria dos Jogos e suas contribuições e limitações no processo de formação de Alianças Estratégicas. Sendo assim, o tema central é a formação de alianças estratégicas e a relação entre estas decisões e a aplicação da lógica da Teoria dos Jogos, principalmente jogos cooperativos, neste processo de formação de relações de cooperação. Este artigo é apresentado como um ensaio teórico e foca na funcionalidade e possível aplicabilidade da Teoria dos Jogos sendo usada no processo de análise e formação de Alianças Estratégicas e estruturas de cooperação. Verificou-se que a Teoria dos Jogos é considerada uma ferramenta matemática e econômica com potencial a agregar no processo decisório de formação de Alianças Estratégicas. Entretanto observa-se que existem algumas limitações metodológicas para a sua aplicação plena, dentre elas o equilíbrio de Nash. Existem condições que devem ser satisfeitas para que se possa aplicar a Teoria dos Jogos de modo satisfatório. Este ensaio conclui com sugestões para estudos futuros.

Palavras-Chave: Alianças Estratégicas; Teoria dos Jogos; Cooperação; Estratégia, Competição.

\section{ABSTRACT}

This study has the objective of discuss and comprehend the application of the Game Theory as its contributions and limitations in the formation process of strategic alliances. The core of this study is the formation of strategic alliances and the relationship between the logic of Game Theory, specifically cooperative games, and the formation of strategic alliances process. This article is presented as an essay and focus on the functionality and the possible application of Game Theory used in the process of analysis and formation of strategic alliances as cooperative structures. It was verify that the Game Theory is considered as a mathematical and economical potential to aggregate functionality to the strategic alliance formation process. However it was verify that there are some methodological limitations in the logic of the game theory such as the logic of the Nash equilibrium. There are some conditions that has to be satisfy so can be used the game theory's contributions. The essay is concluded with some suggestions for future researches.

Keywords: Strategic Alliances, Game Theory, Cooperation, Strategy, Competition.

\footnotetext{
1 Professor Assistente e Coordenador de Pesquisas do Curso de Administração do Centro Universitário Franciscano - UNIFRA. Tem experiência na área de Marketing, com ênfase em Pesquisa de Marketing, análise estratégica e posicionamento de mercado. É atual lider do Grupo de Estudos e Pesquisas em Administração (GEPAD) do curso de Administração da UNIFRA. eduardo@unifra.br
}

Cad. de Pesq. Interdisc. em Ci-s. Hum-s., Florianópolis, v.10, n.97, p. 205-227, jul./dez. 2009 


\section{INTRODUÇÃO}

As alianças estratégicas, atualmente, vêm representando uma forma de aumentar a competitividade empresarial frente ao contexto ambiental turbulento e de difícil acesso. Cada vez mais, os recursos necessários para uma organização não estão mais sob seu alcance direto. Isso faz com que seja necessário adotar uma postura de cooperação com outras organizações. A partir dessa postura podem ser aproveitadas oportunidades de mercado as quais não estariam ao alcance da organização caso ela optasse por agir sozinha.

Tendo em vista as posições de cooperação interorganizacional, as alianças estratégicas são de grande relevância para o estudo da cooperação. Esta postura de cooperação entre organizações tem despertado grande interesse tanto no meio acadêmico como no meio empresarial. Isso se verifica na grande popularização do assunto e na compreensão de que a cooperação entre atores organizacionais é uma postura estratégica muitas vezes necessária para a obtenção de vantagem competitiva no mundo real altamente globalizado e competitivo.

De modo a ilustrar a tendência com relação a este tipo de estratégia empresarial, Harbison \& Pekar (1999) destacam que alianças têm sido formadas me larga escala. Shenkar \& Reuer (2006) também apresentaram a quantidade avassaladora de associações cooperativas entre empresas e o número considerável de pesquisas sobre esse tema em particular. Entretanto cabe ressaltar que essas ligações podem trazer, na sua estruturação, alguns ônus contra os quais nem sempre se tem as ferramentas para evitar: as organizações participantes de uma união enfrentam diversos problemas de conflitos culturais, de poder, de motivação, de relacionamentos, de confiança, de oportunismo ou de organização. Estes problemas podem iniciar durante o processo de formação de uma aliança e acabam por comprometer a durabilidade e a legitimidade do empreendimento conjunto.

Estudos realizados por Harbison \& Pekar Jr. (1999) trazem informações preocupantes quanto ao fracasso de alianças estratégicas. Estes concluíram em seus estudos que entre $55 \%$ e $77 \%$ das alianças fracassam. Outros estudos afirmam que setenta por cento das Joint Ventures acabam indo à falência. Esses índices talvez possam ser explicados porque diversos são os elementos que podem tornar frágil uma estrutura de cooperação. Esses fatores exigem uma atenção especial 
para que os objetivos da união estabelecida sejam devidamente atingidos, porque as principais dificuldades que as empresas encontram para adotar, com sucesso, alianças estratégicas estão relacionadas ao fato de que essas envolvem riscos compartilhados e precisam, portanto, de ajustes mútuos. Este índice de maturidade organizacional associado a uma postura profissional de conhecimento mútuo é necessário para minimizar o risco de insucesso.

O foco deste ensaio teórico é a compreensão da escolha do parceiro para a formação da aliança estratégica. Buscar-se-á verificar alguns dos critérios levados em consideração pelo tomador de decisão no momento de escolher um parceiro, dentre outras possíveis alternativas, para desenvolver um relacionamento cooperativo. Para isso, aborda-se esta análise a luz dos jogos cooperativos de $n$ participantes também com a intenção de contribuir para a Teoria dos Jogos. Este artigo aborda o processo de escolha e formação de uma aliança estratégica e as possíveis contribuições da Teoria dos Jogos já que esta é uma ferramenta analítica e normativa que permite o foco no comportamento interativo dos jogadores e na postura cooperativa, além da competitiva, observando de forma racional os possíveis resultados que serão obtidos de acordo com as estratégias adotadas.

\section{ALIANÇAS ESTRATÉGICAS}

Nas últimas décadas, o cenário mundial tem sofrido mudanças de ordem econômica e social que afetam o mercado e as indústrias de forma cada vez mais significativa. $\mathrm{Na}$ atual conjuntura mundial, onde se observa o avanço da globalização, a alta interdependência no setor econômico e o dinamismo dos mercados, esta postura de alta competitividade já não proporciona os mesmos resultados de alguns anos atrás. Já não mais as organizações possuem acesso direto aos recursos necessários para o sucesso de seus negócios. Assim, a formação de alianças estratégica vem ganhando cada vez mais força como uma postura estratégica no cenário econômico.

O conceito de Alianças Estratégicas é bastante difícil de ser elaborado por existir uma grande variedade de possíveis relações entre as organizações. Segundo Yoshino \& Rangan (1996, p. 5) uma aliança estratégica "é uma parceria comercial que aumenta a eficácia das estratégias competitivas das organizações participantes, 
propiciando o intercâmbio mútuo e benéfico de tecnologias, qualificações ou produtos baseados nesta". Este conceito apresenta uma idéia de benefício mútuo onde os participantes aumentam suas competências atuando de forma cooperativa. Entretanto este conceito ainda é limitado por afirmar que uma aliança estratégica é uma parceria comercial. As justificativas para a sua formação de uma aliança e os interesses dos parceiros envolvidos vão além, na maioria das vezes, de interesses comerciais, mesmo que esses interesses diversos não sejam apresentados de forma explícita. Para o autor existem ainda 3 características que devem ser observadas:

- as duas ou mais empresas que se unem para cumprir um conjunto de metas combinadas permanecem independentes depois da formação da aliança;

- as empresas parceiras compartilham dos benefícios da aliança e controlam o desempenho das tarefas especificadas - talvez o traço mais distintivo das alianças e que muito dificulta sua gestão;

- as empresas parceiras contribuem continuamente em uma ou mais áreas estratégicas cruciais; por exemplo, tecnologia, produtos e assim por diante.

Assim, alianças estratégicas são acordos voluntários de cooperação interorganizacional, muitas vezes caracterizado pela inerente instabilidade gerada pela incerteza relacionada ao comportamento futuro do parceiro e pela aplicação de um nível elevado de autoridade para assegurar o comprometimento (PARKHE, 1993). Este nível elevado de autoridade está relacionado com a estrutura de governança (GULATI, 1998) adotada para monitorar e fiscalizar o relacionamento e os custos de transação existentes (WILLIAMSON, 1985).

Já Contractor \& Lorange (1988) baseiam-se no grau de interdependência entre as partes envolvidas para definir alianças estratégicas. O grau de interdependência pode variar entre alto e baixo, sendo que em um grau de alta interdependência, a reversão da aliança seria mais difícil devido ao próprio grau de dependência entre as partes. Já em uma baixa interdependência, a reversão da aliança poderia ocorrer de forma menos contundente. O grau de interdependência é um parâmetro de grande relevância e que deve ser levando em consideração durante o processo de escolha do parceiro. A Figura 01 ilustra o conceito de interdependência com algumas opções de alianças estratégicas. 


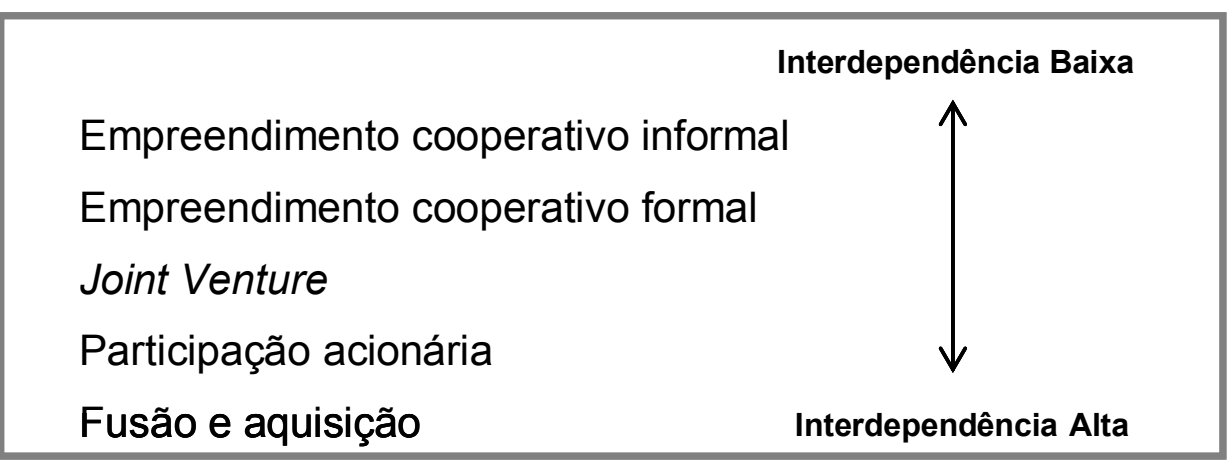

Figura 01: Alianças estratégicas em termos do grau de interdependência entre a empresa-mãe.

Fonte: Contractor \& Lorange (1988).

Entretanto, o conceito de alianças estratégicas a ser utilizado mais propriamente para a análise que se pretende será o de Dussauge \& Garrette (1999, p. 03), que definem alianças estratégicas como sendo:

[...] ligações formadas entre duas - ou mais - empresas independentes que optam por executar conjuntamente um projeto ou atividade específica, coordenando as habilidades e recursos necessários, ao invés de:

- executar o projeto ou atividade por conta própria, assumindo todos os riscos e enfrentando a concorrência sozinho;

- fundir suas operações ou adquirir e se desfazer de unidades de negócios inteiras.

Estas estruturas de cooperação acabam sendo influenciadas e definidas mediante o grau de concorrência e o nível de interação existente entre as partes. A partir do cruzamento entre o nível de concorrência e o nível de interação entre as empresas parceiras, Yoshino \& Rangan (1996) postulam 4 tipos de alianças estratégicas sendo (1) Alianças Pró-Competitivas; (2) Alianças Não-Competitivas; (3) Alianças Competitivas; e (4) Alianças Pré-Competitivas.

Alianças pró-competitivas são alianças verticais entre o fabricante e seus fornecedores ou entre o fabricante e seus distribuidores. Nesses casos, as empresas se unem para aperfeiçoar produtos e processos e, geralmente, não competem entre si. Não ocorre com freqüência, neste caso, a proteção de competências ou de alguns tipos de informação. A ordem é preservar a flexibilidade estratégica e agregar valor às atividades das parceiras. Nas Alianças não-competitivas as empresas desenvolvem o mesmo tipo de negócio, mas nem por isso se vêem como fortes concorrentes entre si. São alianças em que não há concorrência entre as partes, mas, ao contrário das pró-competitivas, exigem um alto grau de interação. Nas 
Alianças competitivas, apesar de as empresas que adotam esta estratégia serem concorrentes diretas, formam alianças com alto grau de interação. É preciso destacar que a possibilidade de aprendizado dentro da parceria constitui uma das principais intenções dos gestores das alianças competitivas. E as Alianças précompetitivas são formadas por empresas que não competem entre si, num primeiro momento, e têm um baixo grau de interação. Ao atingir o objetivo da aliança, as empresas passarão a fabricar e comercializar o produto gerado independentemente. Por isso, tendem a restringir sua interação às atividades essenciais para o desenvolvimento da habilidade planejada por ambas (Yoshino \& Rangan, 1996, p. 20).

\subsection{Motivos para a formação de Alianças Estratégicas}

As alianças estratégicas representam uma opção estratégica para organizações que desejam compartilhar riscos e intercambiar recursos, acessar novos mercados, obter sinergia, alcançar economias de escala e obter vantagem competitiva (DACIN et al., 1997). Também podem ser vistas como arranjos que contribuem para o aprendizado através da integração de tecnologias, habilidades e conhecimento. Kogut (1988) apresenta três motivos gerais para a formação de alianças estratégicas, sendo eles os altos custos de transação, a posição competitiva e o poder do mercado e, por último, a busca pelo conhecimento e pela aprendizagem. Sendo assim, dentre as teorias observadas que explicam a formação de alianças estratégicas encontram-se os custos de transação (ANDERSON \& GATIGNON, 1986; HENNART, 1988), estratégias competitivas (PORTER, 1985), dependência de recursos (PFEFFER \& SALANCIK, 1978), aprendizagem organizacional (KOGUT, 1988), relação social (ANDERSON \& NARUS, 1990), economia política (STERN \& REVE, 1980) e teoria da firma baseada em recursos (DAS \& TENG, 2000).

Além dos motivos citados, organizações formam alianças estratégicas para alcançarem uma série de outros benefícios associados à lógica cooperativa. A formação de uma aliança estratégica, ao invés de uma fusão, por exemplo, proporciona certa liberdade para os seus participantes fazendo com que eles se sintam mais à vontade para aproveitar novas oportunidades externas a aliança. Se 
compararmos o custo de se deixar uma aliança e o custo de se dissolver uma fusão verifica-se que uma aliança estratégica proporciona maior flexibilidade.

Contractor \& Lorange (1988) estabelecem sete motivos relativamente amplos para a formação de estruturas de cooperação sendo (a) redução de risco; (b) obtenção de economias de escala e/ou racionalização; (c) troca de tecnologia; (d) barreira competitiva; (e) barreiras de investimento; (f) facilitação para expansão internacional inicial; e (g) vantagens da quase-integração vertical relacionando contribuições complementares dos parceiros dentro da cadeia de valor. Estas razões acabam facilmente sendo incorporadas no modelo de Kogut (1988) já que estes motivos podem ser classificados como sendo o (1) aumento da competitividade e posicionamento; (2) redução dos custos de transações com atores organizacionais e busca de conhecimento; e (3) aprendizagem organizacional.

Dussauge \& Garrette (1999) ressaltam como característica fundamental de uma aliança a independência das organizações participantes. Dessa forma, a aliança representa a união entre duas ou mais organizações visando atingir um objetivo comum, sem, com isso, abdicar de sua autonomia e independência estratégica. Pelas idéias de Lorange \& Roos (1996), pode-se considerar que a posição estratégica da empresa é de fundamental importância para a análise dos motivos de uma aliança estratégica. Qual seria a importância estratégica do negócio executado pelo possível sócio? Como a aliança estratégica se ajusta às características produtivas do possível sócio ou da empresa-mãe? Além disso, há outra perspectiva com relação à posição estratégica das parceiras. Essa dimensão "considera a posição relativa da empresa em seu negócio; se ela é líder ou mais uma seguidora" (LORANGE \& ROSS, p. 18, 1996). Como líder, ao contrário de uma posição de seguidora, a empresa tenderá a buscar um determinado tipo de aliança estratégica com características inerentes às peculiaridades de sua posição (a líder possui maior participação de mercado, liderança em tecnologia ou qualidade superior). Os autores ainda cruzam essas duas posições estratégicas com quatro motivos genéricos de alianças estratégicas: defesa, aquisição, permanência e reestruturação. 


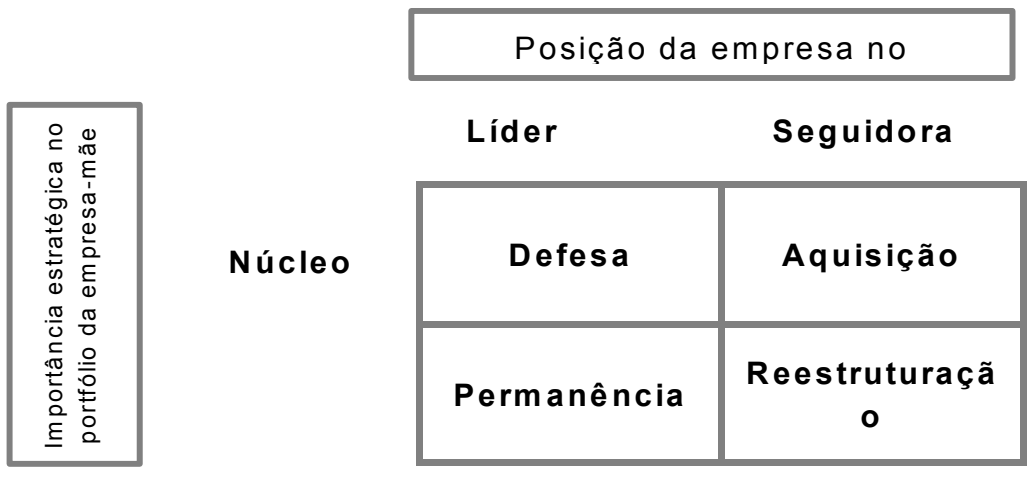

Figura 02: Motivos genéricos para alianças estratégicas

Fonte: Lorange \& Ross (1996, p.18)

Uma classificação bastante ampla que aborda os benefícios alcançados por uma aliança estratégica é a seguinte: os benefícios de uma aliança estratégica podem ser privados ou comuns. Os benefícios privados são aqueles que beneficiam apenas um lado da aliança estratégica. Os benefícios comuns beneficiam ambos os parceiros de uma aliança estratégica (KHENNA et.al., 1998). Esta classificação é observada em alianças de duas organizações. Uma classificação que abranja alianças de mais de dois participantes e que existam acontecimentos que beneficiam alguns dos participantes e não todos ou apenas um deve ser levada em consideração. Sendo assim, existe a possibilidade de existir uma assimetria organizacional em termos de benefícios e vantagens obtidas através da formação de uma aliança estratégica.

Importante é ressaltar sobre as alianças estratégicas assimétricas (BORYS \& JEMISON, 1989). Neste tipo de aliança o poder não é distribuído de forma equilibrada, sendo que uma ou mais organizações têm um poder de barganha maior do que outras. Assim esta distribuição assimétrica faz com que as organizações que detêm a maior concentração de poder exijam um maior controle e, muitas vezes uma maior parcela sobre os resultados. Esta situação de vantagem informacional proporciona a identificação de oportunidades a serem exploradas. Uma aliança estratégica é a opção estratégica lógica quando uma organização está em uma situação de oportunidade em determinada área e sua estrutura organizacional apresenta deficiências ou pontos fracos com relação a competências necessárias para aproveitar as oportunidades existentes. Esta situação justifica a formação de uma aliança estratégica. 
São apresentadas de forma breve, apenas com a finalidade de esboçar sua lógica, duas tipologias de alianças estratégicas. O modelo de Bruno \& Vasconcellos (1996) é composto de cinco etapas: definição estratégica, escolha da parceira, negociação/definição do projeto, implementação/execução e encerramento. O modelo de Harbison \& Pekar (1999) apresenta oito fases para a implementação: definir estratégias e objetivos, selecionar os parceiros, avaliar os fatores negociáveis e a alavancagem, definir as oportunidades, avaliar o impacto sobre os acionistas, avaliar o poder de barganha, planejar a integração e a implementação. A partir da lógica destes dois modelos os quais focam tanto na própria organização como no ambiente cooperativo pretende-se visualizar as contribuições da teoria dos jogos no processo de formação de alianças estratégicas, principalmente nos processos de definição dos objetivos e estratégias e de seleção do(s) parceiro(s).

\subsection{A Formação das Alianças Estratégicas}

O Modelo de formação de Alianças Estratégicas de Yoshino \& Rangan (1996) é subdividido em 4 etapas distintas. A primeira delas, (1) Repensar o negócio, é repensar tanto as estratégias da empresa quanto as novas exigências mercadológicas que pedem diferenciais competitivos. A decisão de estabelecer uma aliança estratégica pode ser crucial à medida que sejam constatadas oportunidades de melhoria, seja para fins defensivos, seja para fins de antecipação. É portanto imprescindível que o papel da aliança dentro da organização esteja claramente determinado.

A segunda etapa é a de (2) Modelar uma aliança estratégica. Esta etapa envolve cinco passos que se relacionam: a desintegração da cadeia de valor e sua posterior reorganização permitem a avaliação de todas as atividades da empresa que geram valor ao que ela produz. Isso exige uma alavancagem interna que permitia realocação de recursos ou a sua concentração. Entretanto, isso só é possível se o parceiro correto for selecionado. A paridade entre as culturas organizacionais, além da sinergia de esforços e de objetivos permitem alinhar recursos, produzindo melhores resultados. Mesmo que esses passos sejam seguidos, ainda assim não há como prever o sucesso da coalizão. Parece prudente, portanto, que seja criada uma posição de recuo e sejam mantidas algumas opções 
estratégicas como defesa, caso o aliado venha a se tornar um adversário, ou mesmo para enfrentar contingências futuras.

$\mathrm{Na}$ terceira é dedicara à (3) estruturação da aliança que constitui um mapa da integração entre as parceiras, estabelece regras e permite avaliar a viabilidade dos objetivos traçados. A estrutura determina os tipos e as quantidades de conhecimentos e competências que serão compartilhados, deixa margem à manutenção de opções estratégicas e permite flexibilidade estratégica, na medida em que as proporções da participação, ao serem visualizadas e analisadas, auxiliam nas decisões mais críticas da alta gerência. E finalmente a quarta e última etapa é a de (4) Avaliar as alianças. É realmente importante que os gerentes estejam atentos às necessidades de intervenção nos rumos da parceria. Se um parceiro não atende aos padrões de qualidade acertados, ou se este não está disponibilizando seus melhores pesquisadores, as empresas precisarão rever suas atitudes.

Outro modelo relevante para este estudo é o Modelo de Lorange \& Roos (1996). Neste modelo percebe-se que existe uma maior atenção por parte dos tomadores de decisão na fase inicial onde esta deve ser detalhadamente analisada e negociada. Em meio às considerações políticas e analíticas que abrangem questões como poder, assimetria informacional, cláusulas contratuais, impacto ambiental e institucional e possíveis efeitos da estruturação da aliança esta fase segue com a aprovação em meio às negociações dos acionistas das empresas envolvidas e com a análise da combinação estratégica das mesmas. A fase intensiva é desenvolvida mediante o apoio interno das organizações e o desenvolvimento do plano estratégico conjunto. $O$ modelo conclui que a aliança é formalizada então através do contrato que rege a estrutura de cooperação. O modelo é demonstrado na figura 03 abaixo. 


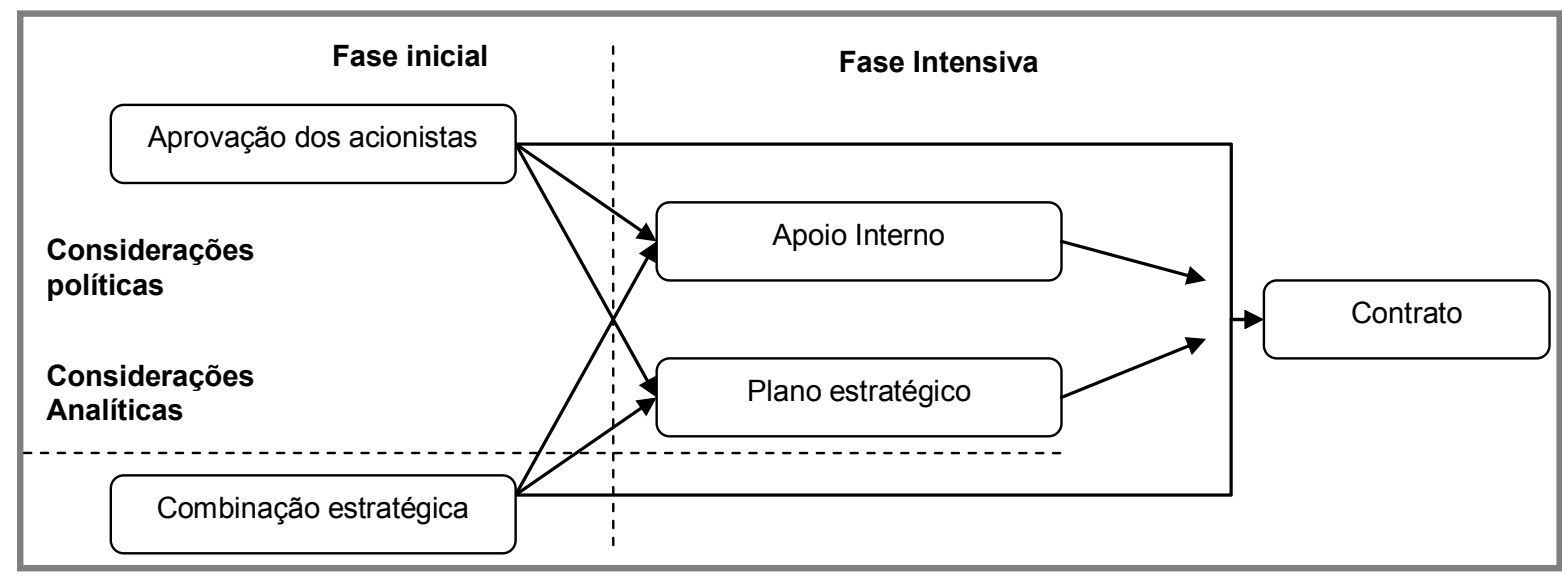

Figura 03: Modelo do Processo de formação de uma aliança estratégica. Fonte: Lorange \& Roos (1996, p. 39).

Logicamente, as análises iniciais são feitas por tomadores de decisões dotados de uma racionalidade limitada (SIMON, 1965). Sendo assim, as confrontar este modelo com alguns preceitos da Teoria dos Custos de Transação percebe-se que por mais que se dedique tempo e esforço para a fase inicial da estruturação de uma Aliança, esta sempre terá falhas que serão levadas ao contrato final. Estas falhas abrem espaço para comportamentos oportunistas que elevam os custos de transação ex-post das relações interorganizacionais (WILLIAMSON, 1985).

Outro modelo pertinente é o de Kanter (1994, p. 98). Segundo o autor o ciclo de relacionamento entre as empresas envolve $o$ início, o crescimento e o desenvolvimento (ou falha - interrupção do processo). Alguns critérios devem ser seguidos nesse processo de cooperação interorganizacional para que se possa garantir o comprometimento dos parceiros e a geração de valor, ou utilidade, para os mesmos. Cada parceiro possui algo de valor que contribui para o sucesso do relacionamento e de seus parceiros. Não mais é possível, para as organizações, desenvolver todas as atividades necessárias para o sucesso do negócio agindo isoladamente. A complementaridade de competências e a interdependência é necessária objetivando uma melhor maneira de se realizar as tarefas necessárias para o sucesso organizacional. Kanter (1994, p. 100) afirma que investimentos mútuos são realizados pelos parceiros tendo em vista uma elevação no nível de comprometimento. Isso pode ser observado como objetivando uma minimização do risco de ações oportunistas por parte dos parceiros e uma redução dos custos de transação. 
Doz (1996) apresenta um modelo evolutivo para o ciclo de cooperação que compreende 4 etapas ou processos principais (FIGURA 04). Este modelo proporcionam um entendimento do quadro evolutivo de uma estrutura de cooperação interorganizacional assim como as posturas estratégicas e processos necessário para seu gerenciamento.

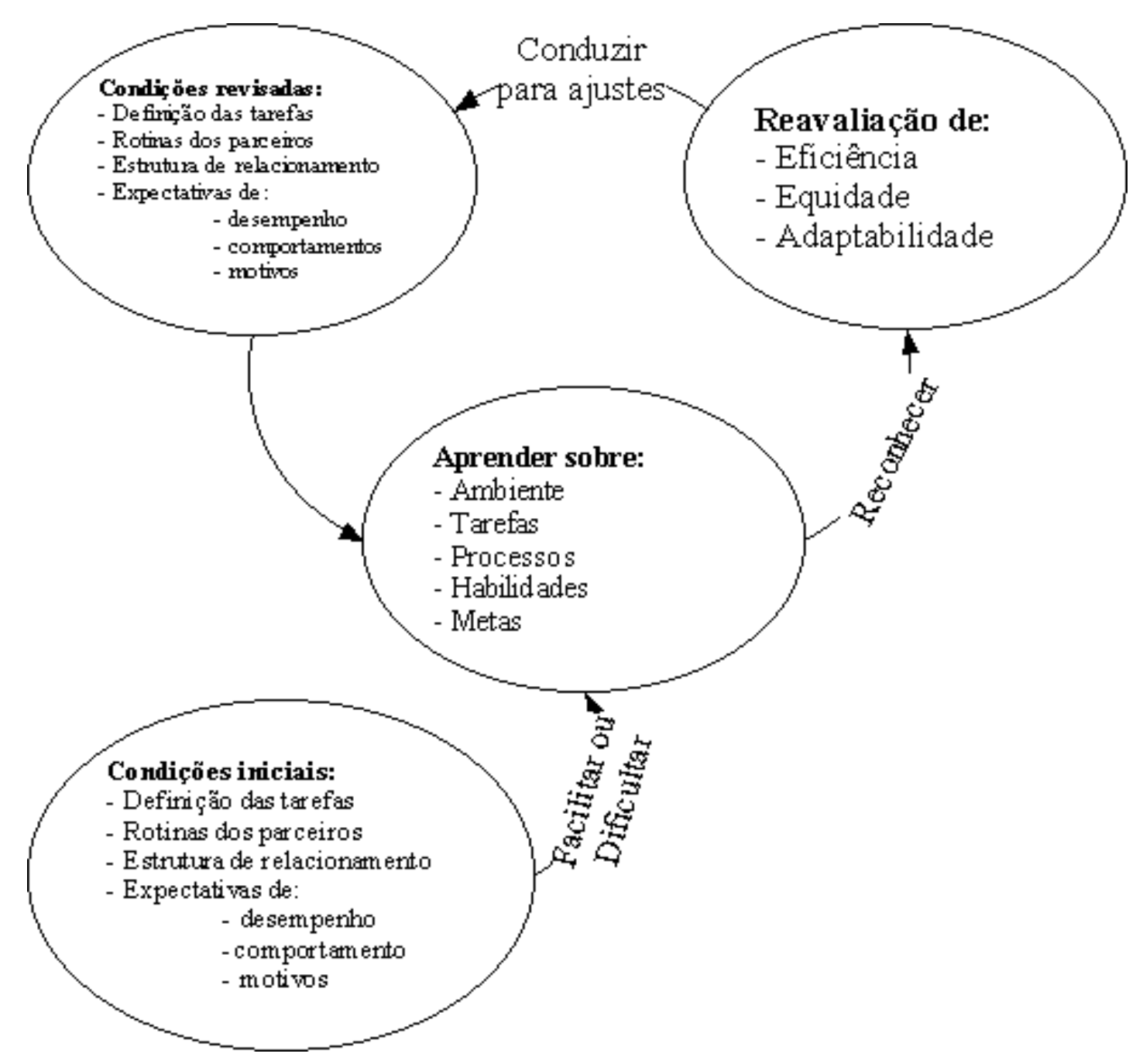

Figura 04 - Processo simplificado do ciclo de cooperação

Fonte: DOZ (1996, p. 64)

A primeira etapa do ciclo proposto por Doz (1996) - condições iniciais - é composta pela definição das tarefas a serem desenvolvidas pelos parceiros, o próprio conhecimento das rotinas de negócio dos parceiros, a estruturação do relacionamento cooperativo e a definição das expectativas sobre a parceria. Em um segundo momento, após a obtenção de um certo nível de comprometimento entre os parceiros, a própria estrutura de cooperação torna possível uma aprendizagem e

Cad. de Pesq. Interdisc. em Ci-s. Hum-s., Florianópolis, v.10, n.97, p. 205-227, jul./dez. 2009 
uma troca de informações. A partir disso, faz-se uma reavaliação e um ajustamento para efetuar as correções necessárias para o melhor desempenho da estrutura de cooperação.

Após este levantamento de algumas teorias e modelos referentes ao tema de Alianças Estratégicas e Relações de Cooperação Interorganizacional é feita uma revisão a respeito da Teoria dos Jogos buscando relacionar a aplicação deste ferramental analítico com o processo de formação e gerenciamento de relações de cooperação.

\section{TEORIA DOS JOGOS}

Em 1944, o matemático John von Neumann juntamente com o economista Oskar Morgenstern publicaram o livro "Theory of Games and Economic Behavior" sendo este considerado o marco inicial da Teoria dos Jogos. O enfoque inicial desta teoria era a aplicação da matemática a situações sociais onde os jogadores agindo de forma racional buscavam os resultados maximizadores a partir da situação estabelecida. A teoria dos jogos é um conjunto de técnicas analíticas destinadas a auxiliar a compreensão de fenômenos observados quando tomadores de decisão, ou jogadores, interagem entre si (OSBORNE \& RUBINSTEIN, 1994). Assim, a teoria dos jogos é o estudo dos meios em que interações estratégicas entre jogadores racionais produzem outcomes relacionados às preferências de cada jogador, sendo estas preferências também chamadas de utilidade.

A Teoria dos Jogos se apóia no princípio da racionalidade instrumental onde os jogadores buscam os melhores resultados para si ou para o grupo. Parte-se do pressuposto de que os jogadores são dotados de uma racionalidade perfeita (racionalidade forte) sendo esse aspecto alvo de críticas de teóricos pragmáticos. Simon (1965, p. 27) afirma que "o processo decisório racional envolve a comparação permanente dos meios alternativos em função dos fins respectivos que procurarão alcançar [...] isto significa que a eficiência, no sentido de obtenção de resultados máximos com meios limitados, deve constituir um critério guiador das decisões administrativas". Assim, busca-se analisar os meios para atingir os fins desejados. Da mesma forma ocorre no processo de seleção de um ou mais parceiros para a 
formação de uma aliança estratégica. Seleciona-se aquele que permitirá que se atinja os fins desejados.

A aplicação da Teoria dos Jogos pode ser de grande relevância para campos de estudo onde o elemento social é influenciador. Segundo Davis (1973, p.15) "[as aplicações da Teoria dos Jogos] não se limitam ao terreno da economia; suas conseqüências se têm feito sentir em ciências políticas, em matemática pura, em psicologia, em sociologia, em finanças e na guerra". Como afirma Oskar Morgenstern, um dos percussores pa Teoria dos Jogos, "a teoria dos jogos é matéria nova que despertou grande interesse em razão de suas propriedades matemáticas inéditas e de suas múltiplas aplicações a problemas sociais, econômicos e políticos. [...] Seus efeitos sobre as ciências sociais já começaram a manifestar-se ao longo de um largo espectro. Suas aplicações se vêm tornando cada vez mais numerosas e dizendo respeito a questões altamente significativas enfrentadas pelos cientistas sociais, mercê do fato de que a estrutura matemática da teoria difere profundamente de anteriores tentativas de propiciar fundamento matemático aos fenômenos sociais" (MORGENSTERN apud DAVIS 1973 p.11).

Desde o seu surgimento, a Teoria dos Jogos já possui uma vasta aplicação teórica. A Teoria dos Jogos enfoca os problemas de decisão de seus participantes e na possível previsão dos comportamentos dos jogadores assim como nos possíveis resultados alcançados. Assim, os insights providos pela Teoria dos Jogos contribuem de forma relevante para o entendimento e compreensão da cooperação estratégica assim como as alianças estratégicas.

Os modelos comumente estudados na teoria dos jogos presumem que cada jogador é racional, isto é, tem plena consciência sobre suas alternativas e expectativas formais quanto aos resultados de eventos aleatórios. Além disto, presume-se que o jogador tem preferências claramente definidas e toma suas decisões após efetuar algum processo de otimização. Assim, a racionalidade impera nos jogos estratégicos. As decisões tomadas são baseadas na Racionalidade Instrumental visando os melhores resultados. O jogador escolherá a estratégia que lhe fará maximizar os ganhos, minimizar as perdas ou então perder se este for o seu interesse visando outros resultados paralelos. Ainda assim, a escolha da estratégia é baseada na racionalidade já que a estratégia atende aos seus interesses. Assumese que o jogador é economicamente racional já que ele avalia os outcomes; calcula 
os caminhos para estes outcomes; e escolhe as ações que o levem aos outcomes preferidos, levando em consideração as ações dos demais jogadores.

A análise da aplicabilidade da Teoria dos Jogos na avaliação de formação de Alianças estratégicas foca na avaliação da utilidade esperada pela relação de cooperação interorganizacional e nos pressupostos da obtenção de equilíbrio. Verifica-se que o conceito de cooperação é de grande relevância para o estudo da teoria dos jogos. O termo cooperar significa agir junto, com um propósito comum (MYERSON, 1991, p. 370). Assim, o jogador deixa de agir individualmente e passa a agir em conjunto com outros jogadores, ao menos em determinados momentos.

A partir desta nova postura, o indivíduo passa a se preocupar não apenas com a sua utilidade individual, mas sim com uma utilidade coletiva. Está ultima é a que justifica o comportamento do grupo que age de forma cooperativa. Assim, para que a aliança seja formada deve-se atender aos interesses e objetivos da racionalidade individual e da racionalidade coletiva. A principal condição motivadora para a formação de uma coalizão, portanto, afirma que o indivíduo não aceitará a obtenção de uma utilidade menor agindo de forma cooperativa do que aquela utilidade que ele obteria agindo individualmente. Uma aliança estratégica, analisada sob a ótica da teoria dos jogos deve satisfazer esta condição primária racionalmente justificada.

Há dois grandes pontos de análise nos jogos cooperativos que devem ser levados em consideração: qual é o payoff para cada coalizão; e qual payoff cada jogador na coalizão deverá optar (VON NEUMANN e MORGENSTERN, 1944). Para esta análise, aplica-se a lógica da Teoria da Utilidade. Em uma situação mais complexa, onde não é óbvio o valor de cada associação ou possível resultado de uma coalizão, cabe utilizar a lógica da Teoria da Utilidade que justifica a elaboração de uma função de utilidade. Segundo Davis (1973, p. 67) "uma função de utilidade é simplesmente 'quantificação' das preferências de uma pessoa com relação a certos objetos". A partir desta quantificação pode-se avaliar o que gera mais utilidade para cada jogador e, assim, compreender o seu comportamento. Partindo do pressuposto de que um jogador possui objetivos e preferências eles buscam a maximização de sua utilidade. Sendo assim, a utilidade refere-se à quantidade de satisfação que um jogador pode ter com relação a determinados objetos, eventos e escolhas estratégicas. 
A utilidade proporcionada por uma Aliança Estratégica deve ser obtida para que se possa aplicar o ferramental analítico da Teoria dos Jogos no seu processo de avaliação e formação. Ao se identificar esta utilidade é possível avaliar os possíveis resultados, ou outcomes, da decisão. Entretanto a quantificação dos possíveis resultados de uma decisão como a formação ou não de uma Aliança Estratégica, ou de sua utilidade esperada pode ser vista como uma critica inicial a sua aplicação. A aplicação da Teoria dos Jogos e de suas soluções pode ser observada como possível em determinados jogos e situações controladas. Já em situações onde incidem uma quantidade incontável de variáveis como no caso de decisões organizacionais, a determinação de uma utilidade esperada é tarefa difícil de ser observada como possível. Borel (1938 apud LEONARD, 1995) questiona a validade dos preceitos da Teoria dos Jogos ao defender a idéia de que em situações reais é pouco provável que se utilizem estratégias que maximizem os resultados de uma decisão.

Críticas comumente encontradas a respeito da sistemática e aplicação da Teoria dos Jogos são referentes a aspectos como os pressupostos comportamentais defendidos pela teoria, assim como a sua lógica dedutiva. A primeira refere-se as imprecisões de se definir os comportamentos maximizadores de resultados dos tomadores de decisões. Isso se dá em grande parte devido aos limites de racionalidade. Outro aspecto que contribui para esta crítica é o de que não necessariamente a racionalidade instrumental seja a única que impere e oriente as decisões dos players. Já com relação a sua lógica dedutiva Lessa (1998) afirma que a Teoria dos Jogos propõe maior valor se utilizada como uma heurística ao invés de uma teoria que propõe soluções derivadas de métodos dedutivos e indutivos. Esta teoria serve a propósitos investigativos que visam aproximar e aperfeiçoar a compreensão da realidade do tomador de decisão ao invés de buscar soluções falsamente perfeitas e inquestionáveis.

Observando estas críticas aplicadas a realidade do processo decisório da escolha e formação de uma Aliança Estratégica verifica-se que estas limitações realmente procedem. A falta de uma visão holística e perfeita dos tomadores de decisões prejudica e impossibilita que sejam verificadas todas as variáveis relacionadas à decisão em si. Não obstante, a racionalidade limitada não permite que se visualize toda e qualquer possibilidade estratégica a que se tem disponível 
assim como não é possível verificar toda e qualquer conseqüência futura de uma decisão específica. Já a aplicação deste método de avaliação, o qual se concentra neste ferramental analítico e matemático proposto pela Teoria dos Jogos, deveria ser visto como um orientador de modo a verificar certos aspectos da interação entre os players. A busca por uma solução matemática perfeita deve ser encarada como duvidosa e até mesmo ingênua já que ao trabalhar com decisões humanas as variáveis matemáticas perdem a sua exatidão.

Outra crítica de grande impacto acadêmico e científico refere-se ao conceito de equilíbrio, altamente difundido e defendido na Teoria dos Jogos. O conceito de equilíbrio é bastante relevante ao se estudar a teoria dos jogos como uma ferramenta analítica normativa e descritiva para a tomada de decisão. Existem dois conceitos de equilíbrio que são fortemente citados nos estudos sobre a aplicação econômica e social da teoria dos jogos. Estes dois conceitos são o de equilíbrio dominante e o de equilíbrio de Nash.

Uma estratégia dominante, segundo Rasmusen (1989) é definida como sendo a melhor resposta para qualquer estratégia adotada pelos demais jogadores. Esta estratégia proporciona sempre o maior payoff. Quando as estratégias adotadas pelos jogadores permanecem inalteradas, ou seja, quando nenhum dos jogadores tem interesse em mudar a sua estratégia, afirma-se que um equilíbrio estratégico foi atingido. O equilíbrio dominante é único e é composto pelas estratégias dominantes dos jogadores. O conceito de equilíbrio de Nash é definido por Tavares (1995) como sendo a combinação de estratégias ótimas de cada jogador, ou seja, a melhor resposta às estratégias dos outros jogadores. Este conceito está intimamente ligado ao conceito de cooperação já que os jogadores atuam de forma a atingir o que é melhor para todos. Entretanto, em determinados jogos mais de um equilíbrio pode ser identificado. Isso resulta em dificuldades metodológicas para a aplicação da teoria em realidades empresariais, inclusive no próprio processo de análise e avaliação da formação de Alianças Estratégicas. Dentre as limitações observadas na aplicação do Equilíbrio de Nash, verifica-se que para o equilíbrio seja alcançado são necessárias que algumas condições sejam satisfeitas. Estas condições são: (1) os participantes do jogo devem se comportar de modo perfeitamente e ilimitadamente racional; (2) não deve haver comunicação prévia ao início do jogo de modo a evitar 
conluios entre os players; e (3) os players devem possuir informações completas e que estas sejam de conhecimento comum de todos.

Entretanto, em alguns jogos não-cooperativos vários equilíbrios de Nash poderiam emergir e, caso não haja um critério bem definido de seleção, as decisões dos players baseadas nestes múltiplos equilíbrios observados poderiam resultar em um comportamento irracional coletivo (KREPS, 1987 apud LESSA, 1998). Sendo assim, o equilibrio de Nash acaba encontrando algumas barreiras de aplicabilidade prática para o processo de identificação, avaliação e formação de alianças estratégicas já que as condições impostas não são observadas na realidade. As próprias condições de simetria informacional e completude de informações assim como o pressuposto de que os tomadores de decisões devem ser dotados de uma racionalidade perfeita afetam negativamente a aplicabilidade prática do Equilíbrio de Nash, mas não o da Teoria dos Jogos que deve ser encarada como um ferramental analítico que deve ser encarado de uma forma heurística.

A partir desta perspectiva de análise e a busca por um melhor entendimento da dinâmica cooperativa existente entre os players pode-se construir um maior entendimento a respeito das possibilidades estratégicas assim como dos próprios limitantes da cooperação que se está buscando criar e manter.

\section{CONCLUSÕES}

Observando o que já foi citado sobre as alianças estratégicas e dos principais motivos que levam organizações a trabalhar em conjunto parte-se do pressuposto de que algumas relações serão mais adequadas aos objetivos previamente estipulados do que outras. Com isso, justifica-se a aplicação da Teoria dos Jogos na análise de formação de alianças estratégicas no momento em que se pode verificar as estratégias de cada jogador e as principais forças motivacionais para a formação deste tipo de relação de cooperação. A afirmação de que determinadas estratégias adotadas por parte das organizações e a complementaridade objetivada pela estrutura cooperativa justificam a formação de determinadas coalizões necessita de maior contribuição empírica sendo esta uma sugestão para futuras pesquisas no campo de estratégias organizacionais. Entretanto, baseado nos objetivos racionais de uma organização, a estruturação de uma relação de cooperação com uma 
determinada organização gerará maior utilidade caso a parceira escolhida satisfaça os requisitos necessários assim como os parâmetros apresentados no decorrer deste artigo como o modelo de Contractor \& Lorange (1988), Kogut (1988), e os demais campos de estudos pertinentes ao estudo da cooperação (dependência de recursos, economia de custo de transação, aprendizagem organizacional, vantagens competitivas etc.).

Através da aplicação da lógica da Teoria dos Jogos pode-se, também, prever de que forma a coalizão preferida irá afetar os demais jogadores, neste caso as demais organizações. A partir do momento em que se opta por determinada coalizão, analisa-se sob uma lógica de jogos competitivos a relação entre a própria coalizão e os outros jogadores. Sendo assim, verifica-se os possíveis resultados das coalizões analisando o jogo sob a lógica cooperativa e a influência que esta coalizão terá sob os demais jogadores adotando a lógica.

Quando, na literatura, algumas tipologias de alianças estratégicas afirmam que se deve observar os objetivos das organizações, avaliar as possíveis opções de alianças, avaliar os possíveis fatores negociáveis e etc., utiliza-se a lógica da Teoria dos Jogos. Para ficar mais claro pode-se citar as oito fazes para a formação de uma aliança estratégica apresentadas por Harbison \& Pekar (1999). O modelo destes autores apresenta oito fases para a implementação: definir estratégias e objetivos, selecionar os parceiros, avaliar os fatores negociáveis e a alavancagem, definir as oportunidades, avaliar o impacto sobre os acionistas, avaliar o poder de barganha, planejar a integração e a implementação. Todas estas fazes seguem a lógica da teoria dos jogos onde se pode melhor observar as escolhas estratégicas e seus possíveis outcomes através de uma análise de jogos cooperativos. É possível então prever as possíveis conclusões que os demais participantes poderão vir a chegar e, com isso, tomas decisões mais acertadas.

Logicamente estas previsões têm limitações impostas pela própria Teoria dos Jogos e das situações necessárias para que a teoria possa ser implementada na prática. A teoria dos jogos ainda tem uma contribuição muito discreta no campo da Administração Estratégica. Entretanto suas contribuições são bastante óbvias e já foram focos de estudos de diversos pesquisadores. Com isso espera-se que futuras pesquisas com foco na Teoria dos Jogos sejam realizadas com a finalidade de explorar esta teoria já que a mesma ainda tem muito a contribuir para o campo da 
Administração Estratégica. Utilizando as classificações e parâmetros inicialmente levantados neste estudo sugerem-se estudos futuros que venham a contribuir com esta discussão teórica e empírica. Dentre estes estudos sugere-se a identificação dos reais motivos que levam os tomadores de decisão a optarem pela formação de Alianças Estratégicas assim como identificar os resultados oriundos destas estruturas de cooperação de acordo com os objetivos iniciais. Logicamente este estudo deverá se configurar como sendo um estudo causal sendo realizado de modo longitudinal. Poderá, desta forma, buscar identificar as motivações iniciais, as assimetrias de informação, os comportamentos dos tomadores de decisão durante todas as fases do processo de formação de uma Aliança Estratégica. 


\section{REFERÊNCIAS}

ANDERSON, E.; GATIGNON, H. Models of foreign entry: a transection cost analysis and propositions. Journal of International Business Studies, v. 17, p. 1-26, 1986.

ANDERSON, J.; NARUS, J. A model of distributor firm and manufacturer firm working relationships. Journal of Marketing, v. 54, p. 42-58, 1990.

BRUNO, Marcos A. C.; VASCONCELLOS, Eduardo. Eficácia da Aliança Tecnológica: estudos de caso no setor químico. Revista de Administração de Empresas (RAE), v. 3, n. 2, p. 73-84, abr./jun. 1996.

BORYS, B.; JEMISON, D. B. Hibrid arrangements as strategic alliances: theoretical issues in organizational combinations. Academy of Management Review, v.14, n. 2, p. 234-249, 1989.

CONTRACTOR, F.J., LORANGE, P. Why should firms cooperate? The strategy and economics basis for cooperative ventures, in Contractor, F.J., Lorange, P. (Eds). Cooperative Strategies in International Business, D.C. Heath, Lexington, MA. 1988.

DACIN, M. T.; HITT, M. A.; LEVITAS, E. Selecting partners for successful international alliances: examination os US and Korean firms. Journal of World Business, v. 32, n.1, p. 3-16, 1997.

DAS, T.; TENG, B. A Resource-based theory of strategic alliances. Journal of Management, v. 26, p. 31-61, 2000.

DAVIS, M. D. Teoria dos Jogos: uma introdução não científica. São Paulo: Cultrix, 1973.

DOZ, Y. L. The evolution of cooperation in strategic alliances: initial conditions or learning processes? Strategic Management Journal, v. 17, p. 55-83, 1996.

DUSSAUGE, P.; GARRETT, B. Cooperative Strategy: Competing successfully through strategic alliances, John Wiley \& Sons Ltd, West Sussex, 1999.

GULATI, R. The architecture of cooperation: managing coordination costs and appropriation concerns in strategic alliances. Administrative Science Quarterly, v. 43, p. 781-814, 1998.

HARBISON, J. R.; PEKAR, Jr., P. Alianças estratégicas: quando a parceria é a alma do negócio e o caminho para o sucesso. São Paulo: Futura, 1999.

HENNART, J. A transaction cost theory of equity joint ventures. Strategic Management Journal, v. 9, p. 361-374, 1988. 
KANTER, R.M. Collaborative Advantage: The Art of Alliances. Harvard Business Review, v. 72, p. 96-108, jul./ago. 1994.

KHENNA, T.; GULATI, R.; NOHRIA, N. The dynamics of learning alliances: competition, co-operation and relative scope. Strategic Management Journal, v. 19, p. 193-210, 1998.

KOGUT, B. Joint ventures: theoretical and empirical perspectives. Strategic Management Journal, v. 9, p. 319-332, 1988.

LEONARD, R. J. From Parlor Games to Social Science: Von Neumann, Morgenstern and the Creation of Game Theory 1928-1944. Journal of Economic Literature, v. 33, p. 730-761, jul. 1995.

LESSA, C. A. Racionalidade Estratégica e Instituições. Revista Brasileira de Ciências Sociais, v. 13, n. 37, jun. 1998.

LORANGE, P; ROOS, J. Alianças estratégicas: formação, implementação e evolução. São Paulo: Atlas, 1996.

MYERSON, R. B. Game theory: Analysis of Conflict. Harvard University Press, 1991.

OSBORNE, M. J.; RUBINSTEIN, A. A Course in Game Theory. Boston: The MIT Press, 1994.

PARKHE, A. Strategic alliance structuring: a game theoretic and transaction cost examination. Academy of Management Journal. v. 36, p. 794-829, 1993.

PFEFFER, J.; SALANCIK, G. The External Control of Organizations: A ResourceDependence Perspective. New York: Harper and Row, 1978.

PORTER, M. Competitive Advantage: Creating and Sustaining Superior Performance. New York: The Free Press, 1985.

RASMUSEN, E. Games and Information - An Introduction to Game Theory. Cambridge: Basil Blackwell, 1989.

SHENKAR, O; REUER, J. J. Handbook of strategic alliances. United States: Sage, 2006.

SIMON, H. A. Administrative Behavior. $2^{\circ}$ Ed. New York: Free Press, 1965.

STERN, L.; REVE, T. Distribution channels as political economies: a framework for comparative analysis. Journal of Marketing, v. 44, p. 52-64, 1980.

TAVARES, M. P. Teoria dos jogos: Algumas aplicações ao mercado de trabalho. Rio de Janeiro: PUC, 1995. 
VON NEUMANN, J.; MORGENSTERN, O. Theory of Games and Economic Behavior. Princeton, NJ: Princeton Universiy Press, 1944.

YOSHINO, Michael Y., RANGAN, U. Srinivasa. Alianças estratégicas: uma abordagem empresarial à globalização. São Paulo: Makron Books, 1996.

WILLIAMSON, O. E. The economic institutions of capitalism: firms, markets, relational contracting. New York: The Free Press, 1985.

Artigo:

Recebido em: 01/07/2009

Aceito em: 09/11/2009 